\title{
CORRECTION \\ Correction: Evolution and study of a copycat effect in intimate partner homicides: A lesson from Spanish femicides
}

\section{José L. Torrecilla, Lara Quijano-Sánchez, Federico Liberatore, Juan J. López-Ossorio,} José L. González-Álvarez

The following information is missing from the Funding statement: The work by QuijanoSanchez has been supported by the Spanish Ministry of Science and Innovation grant FJCI2016-28855.

\section{Reference}

1. Torrecilla JL, Quijano-Sánchez L, Liberatore F, López-Ossorio JJ, González-Álvarez JL (2019) Evolution and study of a copycat effect in intimate partner homicides: A lesson from Spanish femicides. PLoS ONE 14(6): e0217914. https://doi.org/10.1371/journal.pone.0217914 PMID: 31170250

\section{G open ACCESS}

Citation: Torrecilla JL, Quijano-Sánchez L, Liberatore F, López-Ossorio JJ, González-Álvarez $\mathrm{JL}$ (2019) Correction: Evolution and study of a copycat effect in intimate partner homicides: A lesson from Spanish femicides. PLOS ONE 14(10): e0224840. https://doi.org/10.1371/journal. pone. 0224840

Published: October 30, 2019

Copyright: ๑ 2019 Torrecilla et al. This is an open access article distributed under the terms of the Creative Commons Attribution License, which permits unrestricted use, distribution, and reproduction in any medium, provided the original author and source are credited. 